\title{
CARTOGRAFIA DO TURISMO EM SANTIAGO DE COMPOSTELA, ESPANHA
}

\section{TOURISM CARTOGRAPHY IN SANTIAGO DE COMPOSTELA, SPAIN}

\section{CARTOGRAFÍA DEL TURISMO EN SANTIAGO DE COMPOSTELA, ESPAÑA}

\author{
Ivanilton José de Oliveira - Universidade Federal de Goiás - Goiânia - Goiás - Brasil \\ ivanilton.oliveira@gmail.com
}

Pilar Taboada-de-Zuñiga Romero - Universidade de Santiago de Compostela -

Santiago de Compostela - España

pilar.taboadadezuniga@usc.es

\section{Resumo}

Santiago de Compostela, capital da Comunidade Autônoma da Galícia, é um dos principais polos turísticos da Espanha, atraindo milhões de visitantes todos os anos, em função de seu conjunto cultural-arquitetônico e, principalmente, por seu legado religioso, que leva milhares de peregrinos a percorrer os chamados "Caminhos de Santiago". Como consequência, a cidade de Santiago de Compostela desenvolveu uma estrutura turística considerável. 0 objetivo deste trabalho é justamente analisar tanto os dados da demanda, quanto da oferta turística em Santiago, com base no emprego dos métodos cartográficos apropriados para a representação de dados qualitativos, como as tipologias dos atrativos e dos equipamentos turísticos existentes; e dos dados quantitativos, a exemplo da quantidade de visitantes e oferta de hospedagem. Os resultados demonstram que, a representação cartográfica das informações turísticas, permite agregar uma variável geográfica extremamente útil ao planejamento e ordenamento territorial da atividade turística. A análise comparativa da distribuição geográfica da demanda e da oferta turística indica a existência de espaços preferenciais para a prática do turismo, além de uma forte sazonalidade, o que constitui um desafio às políticas e ações governamentais. Por outro lado, os mapas também revelam problemas relacionados à variabilidade espacial de certas informações, como os tipos de hospedagem ou a demanda por certos atrativos turísticos, o que por sua vez permite estabelecer hipóteses para uma investigação específica.

Palavras-chave: cartografia, turismo, análise geográfica, método cartográfico.

\section{Abstract}

Santiago de Compostela, the capital of the Autonomous Community of Galicia, is one of the main tourist centers of Spain. It attracts millions of visitor every year because of its cultural and architectonic assets. The religious heritage, in particular, leads thousands of pilgrims to walk the so-called Way of St. James. As a result, the city of Santiago de Compostela has developed a notable tourism infrastructure. This paper precisely aims to analyze both tourism supply and demand in Santiago. It was based on the use of cartographic methods suitable for representing qualitative data, such as typologies of attractions and existing tourist facilities; as well as quantitative data, like the number of visitors and offers of accommodations. Research results show that the cartographic representation of tourist information allows aggregating an extremely useful geographic variable to planning and spatial planning of tourism. The comparative analysis of the geographic distribution of tourism demand and supply demonstrates the existence of preferred spaces for tourism, plus a strong seasonality, which represent a challenge to government actions and policies. On the other hand, the maps also reveal problems related to the spatial variability of certain types of information. For instance, the kind of accommodation or demand for certain tourist attractions, which, in turn, allow establishing a hypothesis for a specific investigation. Keywords: cartography, tourism, geographic analysis, cartographic method. 


\section{Resumen}

Santiago de Compostela, capital de la Comunidad Autónoma de Galicia, es uno de los principales polos turísticos de España, que atrae a millones de visitantes todos los años, debido a su conjunto culturalarquitectónico y, principalmente, por su legado religioso, lo que motiva a miles de peregrinos a recorrer el "Camino de Santiago". Como consecuencia, la ciudad de Santiago de Compostela desarrolló una considerable infraestructura turística. El objetivo de este trabajo es analizar los datos de la demanda y de la oferta turística en Santiago, con base en el empleo de los métodos cartográficos adecuados para la representación de los datos cualitativos, tales como tipos de atracciones e del equipajes turísticas existentes; y de los datos cuantitativos, como la cantidad de visitantes y la oferta de alojamiento. Los resultados muestran que la representación cartográfica de informaciones turísticas, permite añadir una variable geográfica de gran utilidad para la planificación y el ordenamiento territorial del turismo. El análisis comparativo de la distribución geográfica de la oferta y de la demanda turística indica la existencia de espacios preferidos para la práctica del turismo, y una fuerte estacionalidad, que es un desafío para las políticas y acciones del gobierno. Por otro lado, los mapas también revelan problemas relacionados con la variabilidad espacial de ciertas informaciones, como el tipo de alojamiento o la demanda de ciertos lugares de interés turístico, que a su vez nos permite establecer hipótesis para una investigación específica.

Palabras clave: cartografía, turismo, análisis geográfico, método cartográfico.

Introdução

Santiago de Compostela, Patrimônio da Humanidade (1985), é uma pequena cidade periférica, ao noroeste da Espanha, situada próximo ao centro geográfico da Galícia, e também um dos principais destinos turísticos do continente europeu. Capital da Galícia e sede dos poderes executivo (Xunta de Galicia) e legislativo (Parlamento) da Comunidade Autônoma, pode-se defini-la como uma cidade de tamanho médio entre as cidades galegas, pois tem uma população de aproximadamente 95.800 habitantes (INE, 2014). Contudo, possui uma população flutuante muito maior, formada por estudantes universitários, turistas e por numerosa quantidade de pessoas que se deslocam à capital para trabalhar.

A cidade de Santiago se estrutura em torno de seu sítio histórico, também chamado "a amêndoa", em função da forma do perímetro de sua muralha medieval. Dentro desta encontramos uma riqueza patrimonial única, composta por inúmeros monumentos que refletem a importância histórica da cidade. Não podemos nos esquecer do aspecto religioso do território, marcado por um grande número de igrejas e conventos, que foram nascendo ao redor da catedral durante séculos, situando a cidade como um dos principais destinos religiosos da Europa. Este fato faz com que Santiago de Compostela possua uma singularidade cultural, tanto em seu patrimônio material como imaterial. E, além disso, tem permitido o desenvolvimento 
de um fluxo crescente de visitantes, ao largo das últimas décadas, consolidando a cidade como um destino de turismo cultural e religioso.

A cidade possui boas infraestruturas, grandes recursos patrimoniais, culturais e paisagísticos. E está bem preparada para o acolhimento a visitantes, contando com ampla oferta de hotéis, hostels, bares, restaurantes e cafés. A longa tradição universitária também contribuiu para o desenvolvimento de sua posição como destino e para consolidar uma oferta educativa de qualidade internacional (Taboada-de-Zúñiga, 2014).

Por fim, as instituições governamentais ligadas à atividade turística, como a Turismo de Santiago - Información y Comunicación Local S.A. (Incolsa) e Turismo de Galícia - Turgalícia, bem como o Centro de Estudos e Investigaciones Turísticas (CETUR) da Universidade de Santiago de Compostela (USC), possuem uma boa base de coleta e sistematização de dados sobre a demanda e a oferta turística, o que viabilizou a elaboração do presente trabalho.

\section{Marco Teórico}

Ainda que mapas sejam bastante empregados como ferramentas de promoção do turismo, há, no entanto, uma lacuna quanto à reflexão teórica sobre a relação entre cartografia e turismo.

A maioria dos trabalhos versa sobre o que tem sido chamado de "cartografia turística”, que é na verdade um ramo da cartografia temática, cuja preocupação principal é definir a melhor forma de representar o espaço turístico, sobretudo quanto aos símbolos empregados nos mapas. São desse grupo os textos de Gerber et al. (1990), sobre uma proposta de padronização dos símbolos turísticos; e os de Ostrowski e Ostrowski (1975), Forrest e Castner (1985), Clarke (1989), Morrison e Forrest (1995) e Forrest (1998), que demonstram os resultados de testes sobre a eficiência dos símbolos turísticos em mapas.

Outro enfoque comum é sobre o uso da cartografia como ferramenta de divulgação dos espaços turísticos, como demonstram os trabalhos de Domínguez Mújica (2007), sobre a promoção turística das Ilhas Canárias; Almirón et al.(2007), sobre a promoção turística feita nos mapas da Secretaría de Turismo de Argentina; Barreiro e Gonzáles (2010), sobre a cartografia turística oficial na Galícia; e o de Tujaka (2011), sobre o uso da cartografia para a promoção turística na Internet. 
As exceções são os trabalhos de Kokkonen e Peltonen (1999), que fazem uma análise das fases em que os mapas são utilizados pelo setor do turismo, e os de Oliveira (2007) e Alonso-Monastério (2013), que tratam da importância dos mapas para a interpretação de espaços patrimoniais já incorporados pela atividade turística. Para Menezes e Fernandes (2003), a informação turística é essencialmente geográfica e pode ser trabalhada em dois enfoques distintos: um aplicado ao planejamento turístico, como apoio ao desenvolvimento turístico de um lugar; e outro destinado à orientação dos turistas que visitam um sítio turístico.

Apesar das várias possibilidades de trabalhos, a produção teórica sobre a cartografia do turismo reflete uma subutilização dos mapas no apoio ao planejamento turístico ou na análise geográfica do turismo. Pearce (2003) é uma das poucas exceções, ao empregar os mapas para demonstrar análises quantitativas e qualitativas sobre os padrões e modelos de fluxos turísticos internacionais e domésticos, e sobre as estruturas espaciais do turismo.

Ribera (2008), por sua vez, se refere às funcionalidades da cartografia e dos SIG para o turismo, com destaque principal para os mapas turísticos, mapas de rotas ou itinerários turísticos, a análise territorial e planificação turística, e o geomarketing, apresentando ao final uma proposta de cartografia para a taxa de funcionalidade turística - um índice que mede a relação percentual entre a quantidade de espaços para hospedagem de um destino turístico e a população permanente do lugar.

Oliveira (2005), por outro lado, indica que a cartografia aplicada ao planejamento turístico pode abarcar três enfoques distintos: 1) os mapas para o turismo, quando se faz um trabalho inicial de pesquisa para a implantação de uma atividade turística, como um diagnóstico de potencialidade turística; 2) os mapas sobre o turismo, quando se utiliza a cartografia para analisar e avaliar a atividade turística já existente; e 3) os mapas para turistas, que implica a concepção de mapas para a orientação dos visitantes de um lugar turístico e para a interpretação das paisagens ou do patrimônio (Figura 1).

Godinho e Oliveira (2010) apresentam um exemplo de uso dos mapas sobre o turismo, que analisa e avalia a distribuição da infraestrutura turística de hospedagem e alimentação em uma cidade histórica, comparando-a com a distribuição geográfica das atrações turísticas a fim de compreender sua contribuição para o desenvolvimento do turismo. 


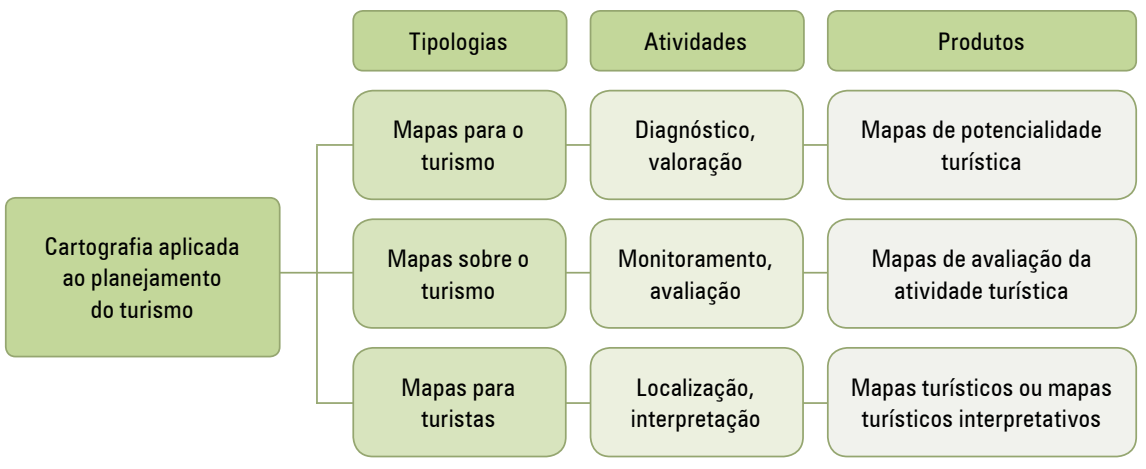

Figura 1 - As possibilidades de aplicação da cartografia em uma análise do turismo Elaborado pelos autores, com base em Oliveira (2005).

Compreendemos que a cartografia do turismo faz parte da cartografia temática e, portanto, segue as mesmas regras pertinentes à comunicação visual realizada por meio das representações gráficas, como os mapas, os gráficos e as redes visuais (fluxogramas, dendrogramas, organogramas etc.).

A representação cartográfica começa pela definição do tema que será cartografado (recorte temático) e dos limites espacial e temporal, que indicam a área a ser representada (recorte espacial) e o período (recorte temporal) que interessam ao trabalho (Figura 2). Essa definição é essencial para a busca dos dados e das fontes de informação ou ainda para se compreender a necessidade de trabalhar não apenas com dados secundários, mas também de se produzir a própria informação (dados primários).

O tema do mapa e o recorte espacial, por sua vez, influem na definição da escala mais adequada, em função do nível de detalhamento que será necessário. A escala e o tema, por outro lado, indicam quais serão a projeção cartográfica e o sistema de coordenadas mais convenientes para o mapa. A forma de representação dos dados como pontos, linhas ou áreas também é uma decisão vinculada ao tema, e às vezes também à escala, já que alguns temas mudam de uma forma a outra (de uma área para um ponto, ou vice-versa) quando se reduz ou se amplia a escala. E, finalmente, o tema e o recorte espacial são determinantes na eleição de uma orientação geográfica para o mapa - que, ao contrário do que pensa a maioria das pessoas, não deve ser obrigatoriamente com o Norte na parte superior do mapa. 


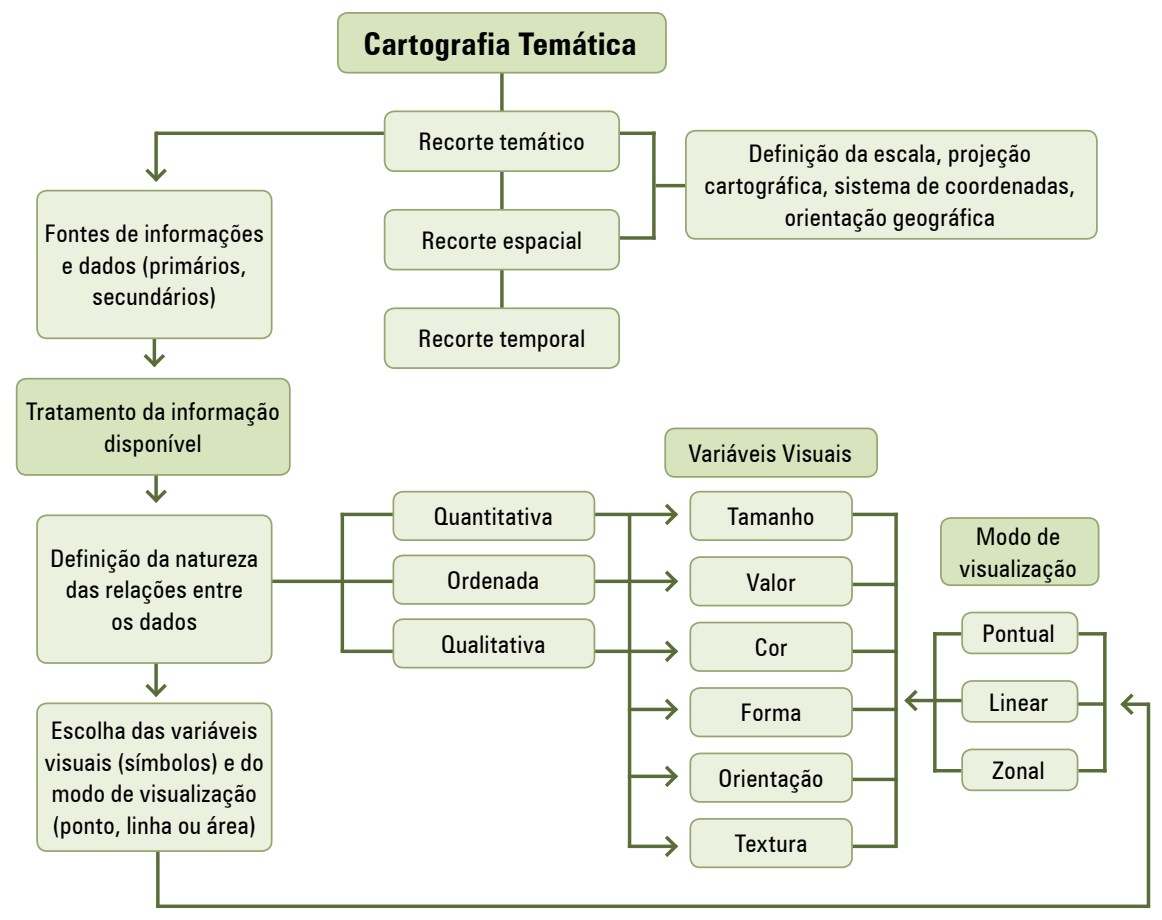

Figura 2 - A sequência de elaboração de um mapa temático

Elaborado pelos autores, com base em Bertin (1967), Martinelli (1991), Oliveira e Romão (2013).

Com os dados do tema já disponíveis, é necessário fazer o tratamento da informação, que consiste basicamente em identificar a natureza das relações entre os dados (quantitativa, ordenada ou qualitativa). Quando se trabalha com uma grande quantidade de dados, especialmente os quantitativos, muitas vezes é necessário recorrer a um tratamento estatístico, como um agrupamento em classes de intervalos dos valores (regulares ou não); ou um agrupamento por tipologias, quando se trabalha com dados qualitativos. A etapa seguinte é escolher as variáveis visuais mais adequadas (os símbolos). Ou seja, de fato, se inicia o mapa pela concepção de sua legenda. 


\section{Metodologia}

Para realizar o trabalho de cartografar o turismo na cidade de Santiago de Compostela, escolhemos algumas variáveis da demanda e da oferta turística como nosso recorte temático e trabalhamos principalmente com dados secundários (Quadro 1). Mas também realizamos várias incursões pela cidade, ao longo dos meses de setembro a dezembro de 2014, para registrar alguns dos lugares de interesse turístico, com fotografias e as respectivas localizações geográficas. O recorte temporal para os dados secundários é o ano de 2013, em função da possibilidade de acesso a informações das fontes disponíveis. E o recorte espacial foi definido como um retângulo envolvendo o casco antigo da cidade, onde se concentra a maioria dos atrativos turísticos e grande parte dos equipamentos turísticos (hotéis, restaurantes, bares e cafeterias).

\begin{tabular}{|c|c|c|c|}
\hline \multicolumn{2}{|c|}{ Tipo } & Variáveis & Fontes \\
\hline \multirow{7}{*}{$\begin{array}{l}\text { Oferta } \\
\text { turística }\end{array}$} & \multirow{4}{*}{$\begin{array}{l}\text { Atrativos } \\
\text { turísticos }\end{array}$} & $\begin{array}{l}\text { Igrejas e conventos: localização, idade, } \\
\text { estilo arquitetônico }\end{array}$ & $\begin{array}{l}\text { Pesquisa na Internet e trabalho } \\
\text { de campo }\end{array}$ \\
\hline & & $\begin{array}{c}\text { Edifícios históricos: localização, idade, } \\
\text { estilo arquitetônico }\end{array}$ & $\begin{array}{l}\text { Pesquisa na Internet e trabalho } \\
\text { de campo }\end{array}$ \\
\hline & & Museus: localização, categoria & $\begin{array}{c}\text { Pesquisa na Internet e trabalho } \\
\text { de campo }\end{array}$ \\
\hline & & $\begin{array}{l}\text { Parques, jardins e fontes: localização, } \\
\text { descrição }\end{array}$ & $\begin{array}{l}\text { Pesquisa na Internet e trabalho } \\
\text { de campo }\end{array}$ \\
\hline & \multirow{3}{*}{$\begin{array}{l}\text { Equipamentos } \\
\text { turísticos }\end{array}$} & $\begin{array}{l}\text { Hotéis, pensões, albergues: endereço, } \\
\text { categoria, quantidade de quartos e camas }\end{array}$ & Turismo de Galícia - Turgalícia \\
\hline & & $\begin{array}{l}\text { Restaurantes, bares e cafeterias: } \\
\text { endereço, categoria }\end{array}$ & Turismo de Galícia - Turgalícia \\
\hline & & $\begin{array}{c}\text { Centros de informações turísticas: } \\
\text { endereço }\end{array}$ & $\begin{array}{l}\text { Pesquisa na Internet e trabalho } \\
\text { de campo }\end{array}$ \\
\hline \multirow{3}{*}{\multicolumn{2}{|c|}{ Demanda turística }} & $\begin{array}{l}\text { Número e origem dos visitantes nos } \\
\text { museus }\end{array}$ & $\begin{array}{l}\text { Informações enviadas pelas } \\
\text { direções dos museus }\end{array}$ \\
\hline & & Número e origem dos peregrinos & $\begin{array}{c}\text { Centro de informação turística ao } \\
\text { Peregrino - Xacobeo }\end{array}$ \\
\hline & & $\begin{array}{l}\text { Número e origem dos visitantes nos } \\
\text { centros de informações turísticas }\end{array}$ & $\begin{array}{l}\text { Turismo de Santiago - Incolsa } \\
\text { Turismo de Galícia - Turgalícia }\end{array}$ \\
\hline
\end{tabular}

Quadro 1 - Variáveis do recorte temático da pesquisa

Organizado pelos autores. 
A base de dados cartográficos utilizada no trabalho foi a oficial, em formato shapefile, disponível para download no portal na internet da Diputación de A Coruña, Encuesta sobre Infraestructuras y Equipamentos Locales (webEIEL). Os temas utilizados foram: ruas, edificações, parques e hidrografia. Todos disponíveis em escala 1:5.000, com período de elaboração original entre 2004 e 2006, e associados ao sistema de referência European Petroleum Survey Group - EPSG, UTM Zona 29 N.

O método cartográfico adotado para o tratamento e representação dos dados qualitativos envolveu a categorização e o consequente agrupamento por afinidade temática, quando necessário. Já os dados quantitativos foram tratados com base no método de figuras geométricas proporcionais, que consiste em transcrever os valores numéricos por variações dimensionais dos símbolos, mantendo a proporcionalidade entre eles; ou por meio do método coroplético, em que os valores numéricos são agrupados em classes de intervalos e transcritos por variações visuais de tonalidades de uma cor ou sequência ordenada de matizes (Martinelli, 1991). Para algumas variáveis quantitativas optou-se pela representação por meio de diagramas de setores, de barras ou de linhas, dependendo da natureza das relações entre os dados.

\section{Resultados e discussões}

\section{Distribuição geográfica da oferta turística: os atrativos de Santiago de Compostela}

Ao todo, a cidade de Santiago possui 28 igrejas, conventos e monastérios; 23 museus, galerias e fundações culturais; 19 grandes edifícios históricos; e 16 parques e jardins. Convém destacar que nem todos os locais foram incluídos no mapeamento - a exemplo das fundações e galerias de arte -, em função de não se enquadrarem, de fato, como atrativos turísticos, haja vista que muitos não são abertos à visitação regular.

O mapeamento revela uma concentração muito forte dos atrativos turísticos relacionados ao conjunto cultural-arquitetônico na área do casco antigo de Santiago (la almendra). Já os parques e jardins, que constituem outra modalidade de atrativo turístico, embora pouco explorada no marketing turístico local, estão majoritariamente no entorno do casco antigo (Figura 3). 
Como a maioria dos visitantes se concentra justamente na área do casco antigo, a divulgação dos parques exigiria uma estratégia diferenciada, no sentido de levar os turistas a se aventurarem além dos limites do sítio histórico. Por outro lado, a grande concentração de atrativos histórico-culturais no casco exige um planejamento adequado dos acessos e das condições de mobilidade, tanto para visitantes quanto para os moradores de Santiago - algo que no momento, a julgar pela avaliação prévia realizada durante as incursões de campo, não parece existir.
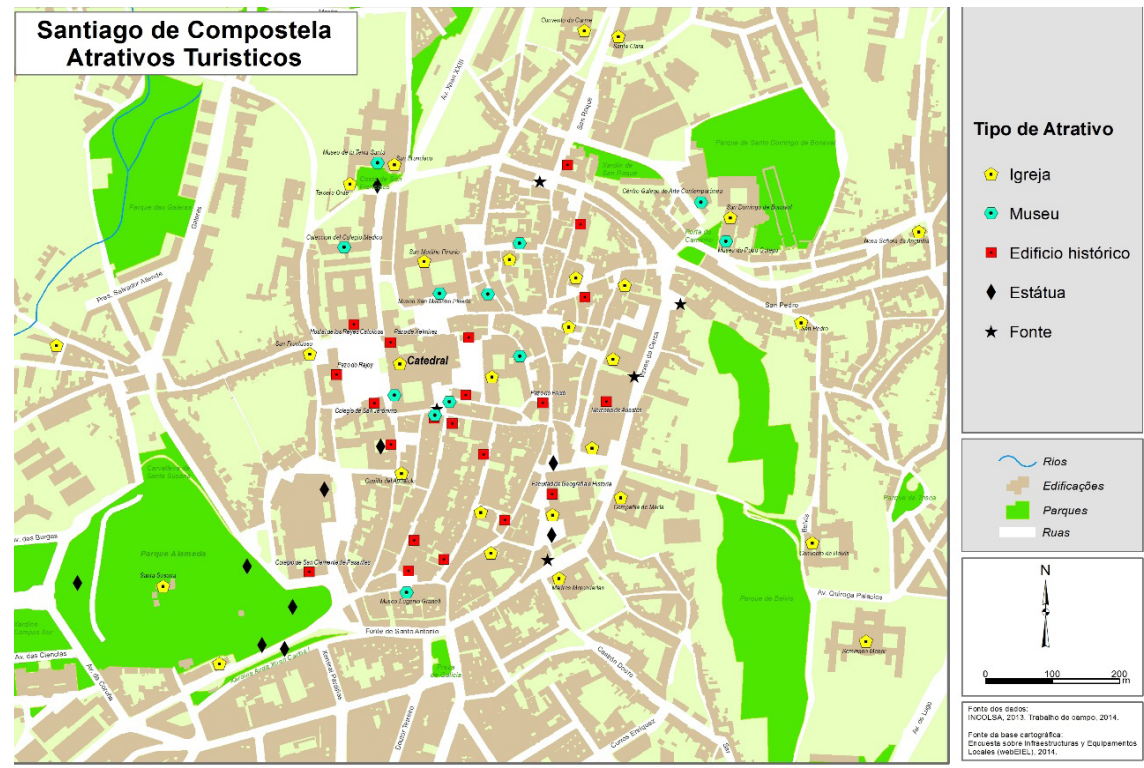

Figura 3 - Mapa dos atrativos turísticos de Santiago de Compostela

Elaboração própria (2015).

O marketing turístico de Santiago carece também de instrumentos de interpretação do patrimônio cultural arquitetônico, que valorizem o fato de a cidade possuir edificações que datam desde o século IX ao século XVIII, e estilos arquitetônicos variados, como o românico e gótico, embora a grande maioria seja de estilo barroco. O mesmo se pode dizer em relação às fontes, algumas com séculos de existência, e as estátuas e representações dispostas nos espaços públicos, que são pouco divulgadas. 
Distribuição geográfica da oferta turística: os equipamentos turísticos

Santiago é uma cidade privilegiada em relação à oferta de estabelecimentos de hospedagem e alimentação. A cidade oferece 65 hotéis, 116 pensões e hostels, além de albergues, campings e, mais recentemente, apartamentos turísticos. Registra, ainda, o impressionante número de 408 restaurantes e 85 cafeterias (alguns desses estabelecimentos são também bares).

Os dados sobre os estabelecimentos relacionados à hospedagem indicam uma inversão da situação vista entre os atrativos turísticos, em relação à área do casco antigo e o seu entorno (Figura 4). Há uma clara predominância da oferta de vagas fora do sítio histórico, o que é de certa forma normal, haja vista que a área do casco antigo apresenta restrições quanto a novas edificações ou ampliação e mesmo adequação dos espaços já existentes, para criação de hotéis. Por isso mesmo, predominam ali os hotéis, pensões e hostels com menor capacidade, embora sejam em grande número de estabelecimentos (Figura 5).

\section{Número de quartos}

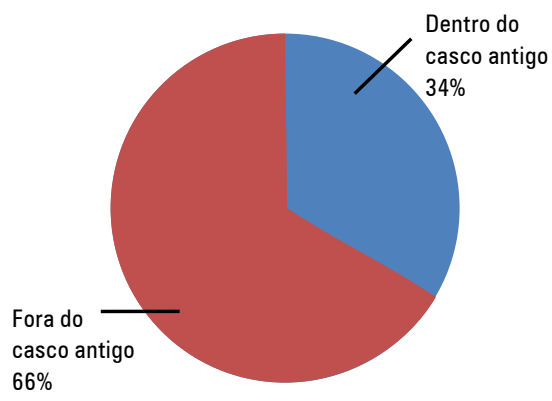

\section{Número de camas}

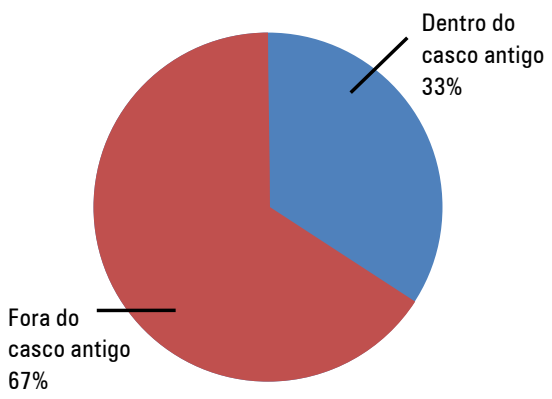

Figura 4 - Comparação entre o número de hotéis e camas fora e dentro do casco antigo de Santiago de Compostela 

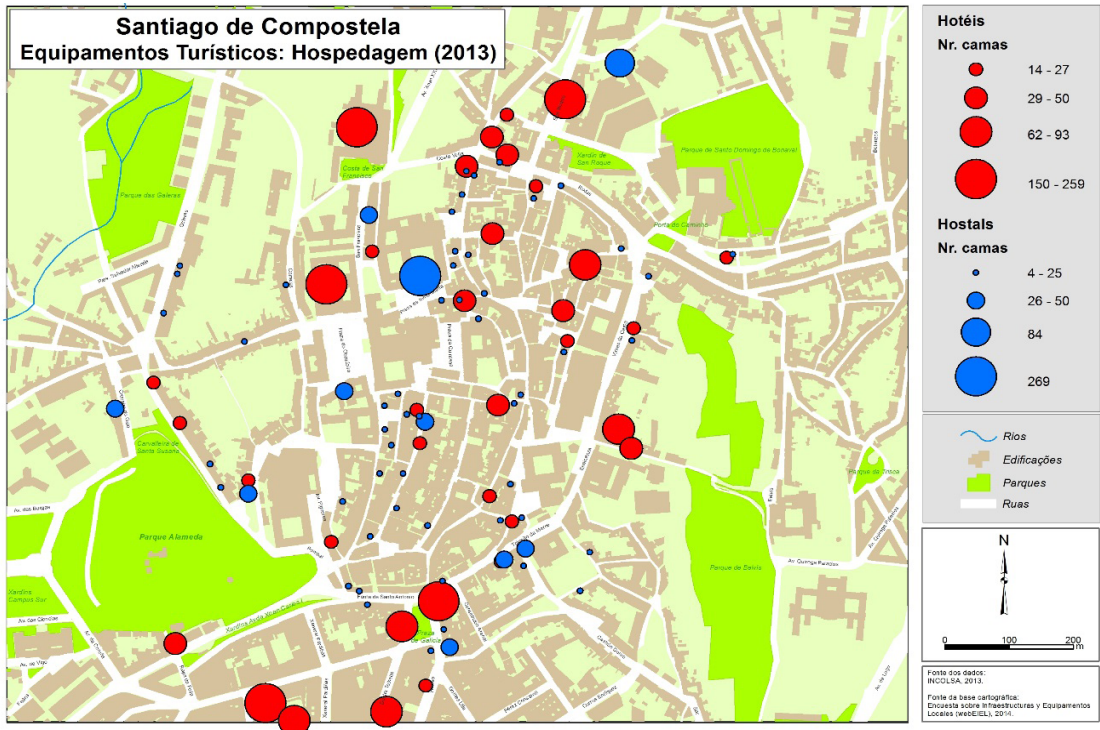

Figura 5 - Mapa da oferta quantitativa de hospedagem em Santiago de Compostela Fonte dos dados: Agencia Galega de Turismo (2014). Elaboração própria (2015).
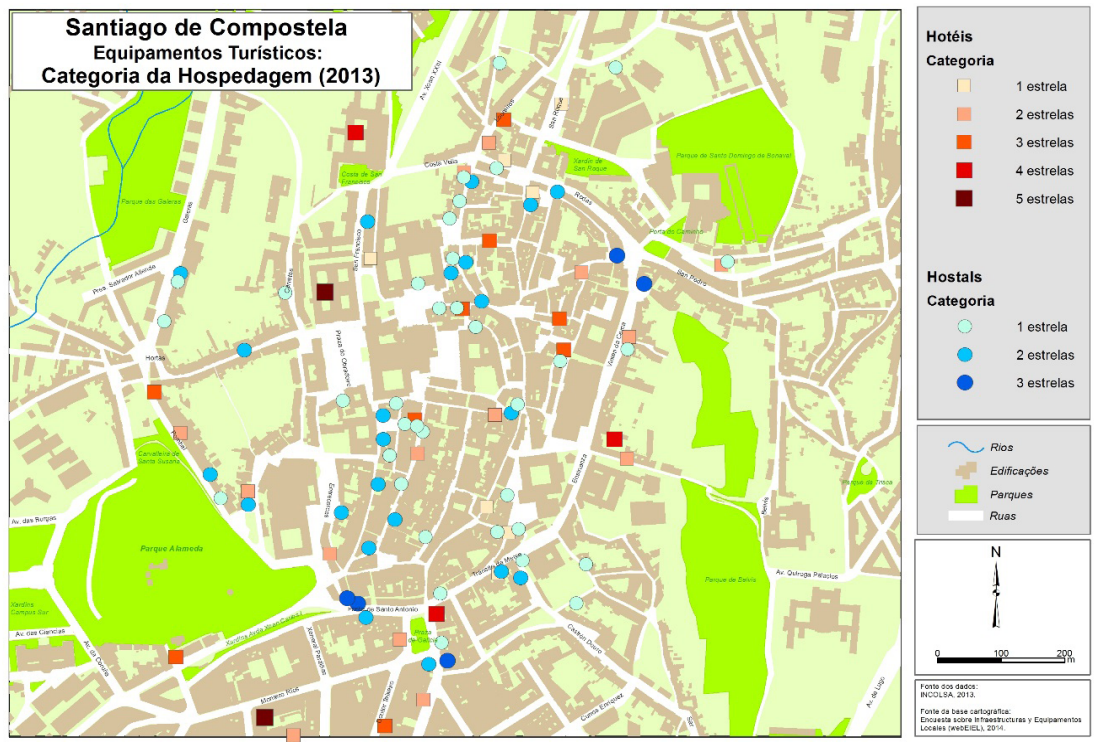

Figura 6 - Mapa da oferta qualitativa de hospedagem em Santiago de Compostela Fonte dos dados: Agencia Galega de Turismo (2014). Elaboração própria (2015). 
Já em relação à categoria, o mapeamento (Figura 6) revela uma concentração das pensões e hotéis de categorias inferiores ou intermediárias no casco antigo, enquanto os estabelecimentos de categorias superiores ocupam as áreas do entorno. Esse mapa permite perceber também a supremacia do número de pensões (hostels) em relação ao de hotéis na área do sítio histórico de Santiago, o que reflete uma tendência comum nas grandes cidades, especialmente as europeias, em função da menor exigência de infraestrutura e pessoal nesse tipo de estabelecimento, que também se adaptam mais facilmente aos poucos espaços disponíveis, geralmente exigindo menor intervenção nas áreas edificadas.

A distribuição do número de quartos e camas entre as diversas categorias dos hotéis (de 1 até 5 estrelas) também revela a predominância da oferta entre categorias mais simples na área do casco antigo (Figura 7) e o inverso na área fora do sítio histórico (Figura 8). Contudo, a cidade se caracteriza por uma oferta de alojamentos de alta qualidade, já que $21 \%$ do setor hoteleiro se concentra nas categorias de 4 e 5 estrelas. Além disso, o número de quartos destas categorias representa mais da metade da oferta total (52\%).

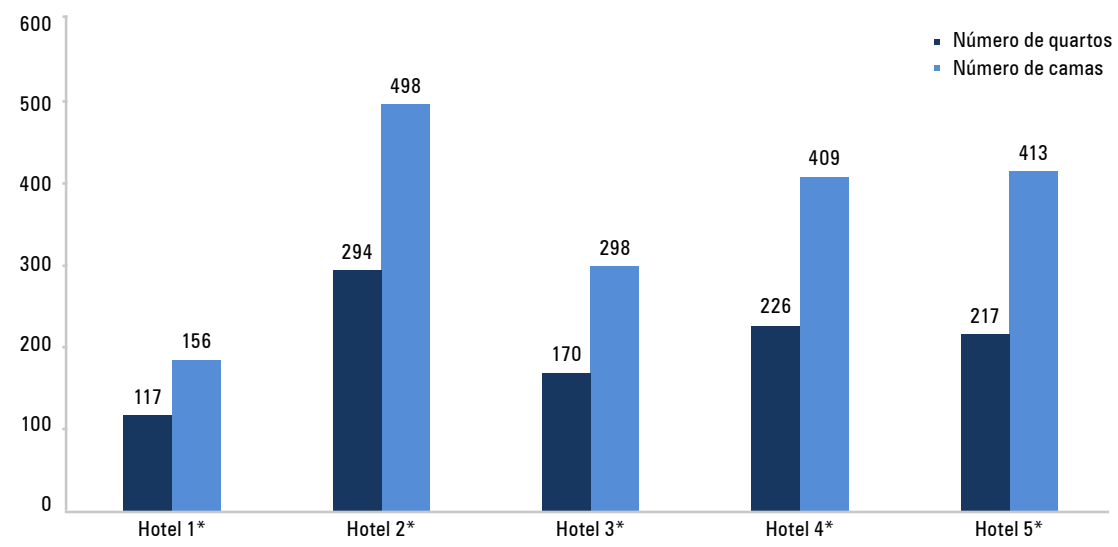

Figura 7 - Número de quartos e de camas nos hotéis, por categorias, no casco antigo de Santiago Fonte: Agencia Galega de Turismo (2014). Elaboração própria (2015). 


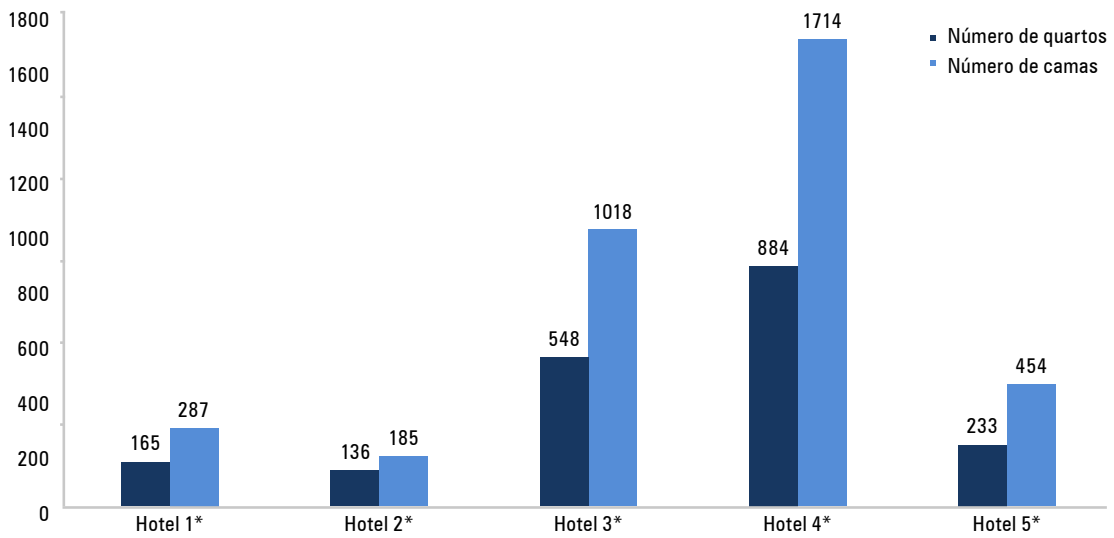

Figura 8 - Número de quartos e de camas nos hotéis, por categorias, fora do casco antigo de Santiago Fonte: Agencia Galega de Turismo (2014). Elaboração própria (2015).

As pensões e hostels também se apresentam como um elemento marcante do cenário da infraestrutura de hospedagem em Santiago, pois ainda que não se caracterizem por apresentar uma grande quantidade de número de quartos/camas, no entanto, são bastante numerosos (117 estabelecimentos) e, além disso, estão bem distribuídos entre o casco antigo (54\%) e o entorno (46\%).

\section{Distribuição geográfica e temporal da demanda turística}

A demanda turística em Santiago de Compostela está concentrada majoritariamente no casco antigo da cidade (Figura 9), destacando-se apenas dois atrativos muito visitados que ficaram fora do recorte elegido para o estudo: a Cidade de la Cultura, que fica um pouco afastada da área urbana, à leste, e o Museo de Historia Natural, que pertence à USC e está em seu Campus Norte, bem próximo ao casco. 


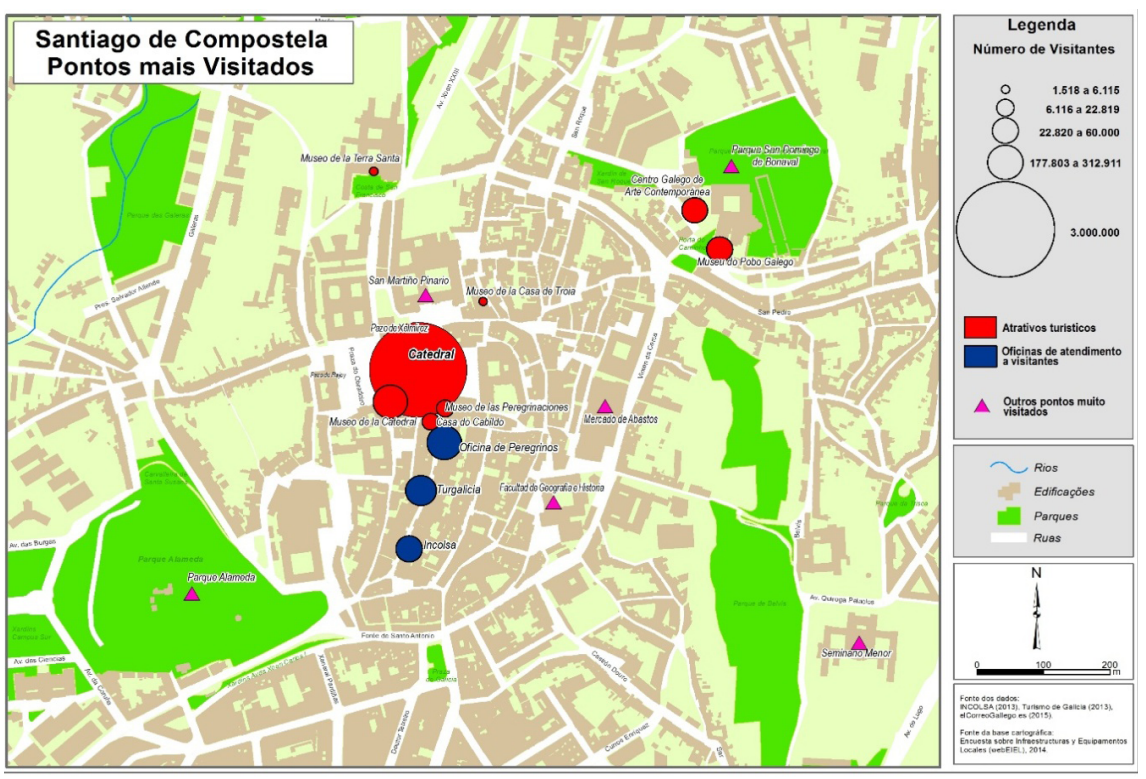

Figura 9 - Pontos mais visitados em Santiago de Compostela

Fonte dos dados: Agencia Galega de Turismo (2014). Elaboração própria (2015).

Cabe destacar que nem todos os atrativos turísticos possuem ou informam estatísticas sobre o número correto de visitantes a cada ano (ou mês), o que nos permite afirmar que os resultados apresentados no mapa são subdimensionados em relação ao total correto de turistas e peregrinos que circulam pelos pontos turísticos de Santiago.

A demanda turística, ao nível de toda a Comunidade Autônoma da Galícia, apresenta uma distribuição temporal com elevado índice de sazonalidade e uma grande concentração geográfica, apesar de nos últimos anos os órgãos gestores do turismo terem desenvolvido campanhas de promoção específicas de diversificação da oferta e ao mesmo tempo apostarem na criação de produtos com menor índice de sazonalidade. Essa temporalidade se concentra principalmente na época do verão: julho, agosto e setembro. A concentração geográfica se dá tanto na origem como no destino. Quanto à origem, os focos emissores se nutrem principalmente do turismo interno ou doméstico. E quanto ao destino, se repartem 
fundamentalmente entre as zonas costeiras e em alguns pontos do interior, entre eles Sanxenxo e Santiago de Compostela.

Em relação a Santiago, os dados disponíveis são do Instituto Nacional de Estadística (INE) e do Observatorio del Perfil de la Demanda Turística de Santiago de Compostela, realizado pelo CETUR-USC. O primeiro elemento a assinalar é que a cidade recebe um elevado número de visitantes, dentre os quais os peregrinos e excursionistas têm um papel muito importante. A cada ano chegam à cidade mais de 500 mil viajantes, ainda que nos anos de Jubileu (Año Santo Jacobeo) essa cifra aumente consideravelmente alcançando 704.107 viajantes no ano de 2010 (Figura 10).

\section{Total de viajantes que pernoitam (2005-2014)}

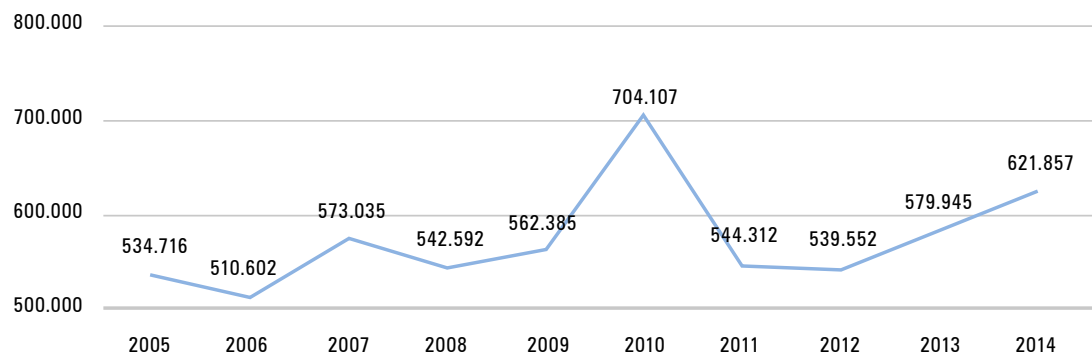

Figura 10 - Evolução da demanda de viajantes que pernoitam em Santiago de Compostela Fonte: INE, 2014. Elaboração própria (2015).

Nr. dias

Permanência média dos turistas (2005-2014)

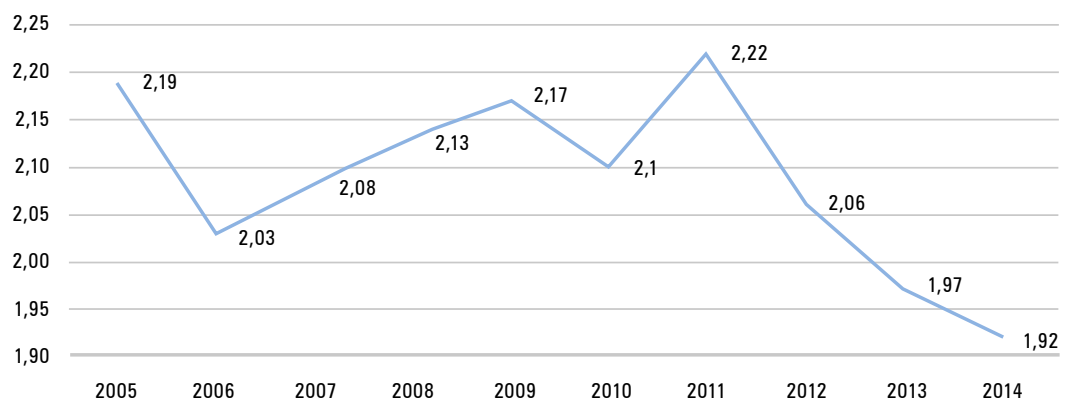

Figura 11 - Tempo médio de permanência dos turistas em Santiago de Compostela Fonte: INE, 2014. Elaboração própria (2015). 
A permanência média no destino gira em torno de 2 dias (Figura 11), ainda que nos últimos anos essa cifra apresente tendência de baixa, talvez devido à crise econômica que afeta a Espanha já há alguns anos e também porque muitas vezes a oferta turística disponível na cidade não incita a uma maior permanência, fato que leva a refletir sobre a necessidade de se pensar em novos produtos, e na coordenação de ações por parte dos ofertantes.

Uma das características do turismo em Santiago, além de sua concentração espacial na parte antiga da cidade, é sua forte sazonalidade, o que faz com que nos meses de verão a cidade fique cheia de visitantes, afetando sobremaneira o sítio histórico e, como consequência, criando problemas de capacidade de carga. Esse fato produz um efeito negativo com relação ao turismo por parte da população local, a qual demonstra, muitas vezes, certo mal-estar diante da avalanche de turistas em zonas-chave de passagem, como o são as ruas do Vilar, Franco e a Praça do Obradoiro, ou mesmo no comprometimento da travessia da catedral, como o fazem cotidianamente.

\section{Número de viajantes que pernoitam em 2014}

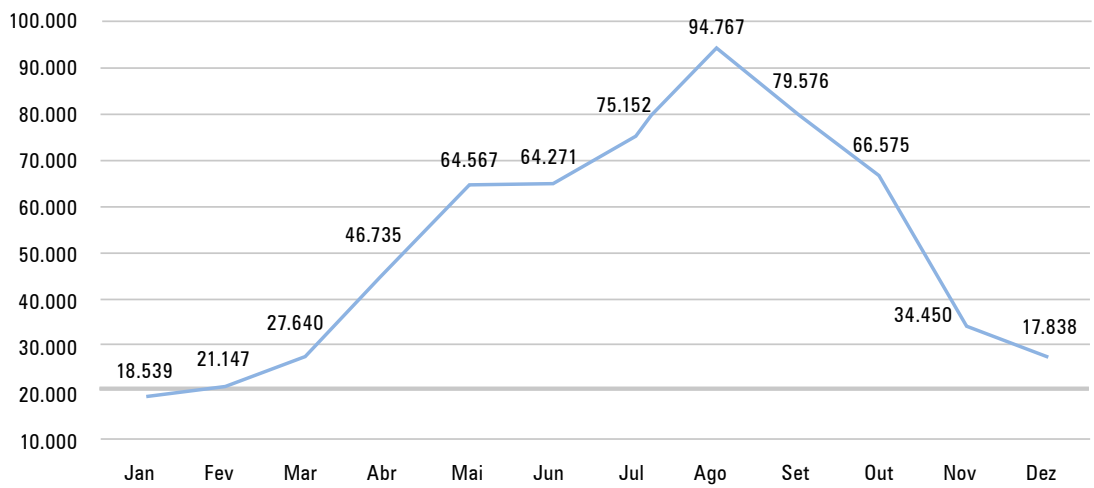

Figura 12 - Evolução da demanda mensal de turistas em Santiago de Compostela no ano de 2014 Fonte: INE, 2014. Elaboração própria (2015).

É necessário ressaltar, ainda, que a forte sazonalidade (Figura 12) produz efeitos negativos sobre o emprego turístico, pois alguns hotéis e estabelecimentos de alimentação fecham as portas em janeiro e fevereiro, 
considerados períodos de baixa ocupação/baixo consumo. Por esse motivo, faz-se necessário tomar medidas para combater a instabilidade na demanda, a exemplo da criação de produtos com um caráter menos estacional, além de se segmentar mais a demanda e buscar novos polos emissores.

\section{Conclusões}

A Espanha é um dos países com mais conjuntos histórico-artísticos declarados como Patrimônio da Humanidade, o que motiva a transformação de seus produtos culturais em produtos turísticos. E observa-se que o mercado de viagens culturais é um mercado em plena expansão, já que o turista cultural realiza um gasto maior, é menos invasivo e contribui para projetar positivamente a imagem de um país (Taboada-de-Zúñiga, 2012).

Os centros históricos servem para atribuir identidade e permitem diferenciar as cidades, ao constituir espaços do passado e, em grande medida também, a memória coletiva de uma sociedade. Por esse motivo, consideramos que a cartografia é fundamental para promover os sítios históricos de uma forma profissional, ao permitir que: 1) o visitante tenha acesso a uma informação qualificada sobre os recursos turísticos do destino; 2) os agentes turísticos, a exemplo dos que trabalham nos centros de informação de turismo, possam orientar o turista de uma maneira mais dinâmica e organizar diversos itinerários alternativos aos habituais; e 3) aos gestores, na tomada de decisões sobre o planejamento territorial da atividade turística, possam dispor de análises pormenorizadas sobre a distribuição geográfica da demanda e da oferta turísticas.

Consideramos, ainda, que o trabalho cartográfico deve estar conjugado a todo um conjunto de informações visuais sobre o turismo, a exemplo da sinalização dos cascos históricos, que em Santiago de Compostela, por exemplo, é um aspecto que ainda deixa a desejar. Faz-se necessária uma renovação ou melhora da sinalização dos recursos turísticos da cidade, bem como uma nova cartografia turística. Em primeiro lugar porque se trata de uma demanda expressa pelo setor turístico da cidade e detectada como um aspecto a ser melhorado, nas pesquisas de satisfação realizadas com os visitantes da cidade ${ }^{1}$. Além disso, Santiago de Compostela é depositária de um dos legados do patrimônio histórico-artístico mais importantes do mundo e, por esse motivo, faz jus a uma atuação mais incisiva quanto à valorização da comunicação visual do 
turismo, se se objetiva seguir mantendo os níveis de qualidade na imagem e na marca desse destino turístico de fama mundial.

\section{Nota}

1 No documento Informe del Perfil de la Demanda Turística (ano 2013), realizado pelo Centro de Estudos e Investigacións Turísticas, a valoração da sinalização turística da cidade teve uma nota de 4 pontos (sobre um total de 5). E já no Informe do ano de 2014, a valoração foi inferior $(3,8$ sobre 5 pontos).

\section{Referências}

AGENCIA GALEGA DE TURISMO - TURGALICIA. Observatorio Turístico. Datos estatísticos. 2014. Disponível em: <http://www.turgalicia.es/aet/portal/index. php?idm=11>. Acesso em: 20 ago. 2015.

ALMIRÓN, A.; TRONCOSO, C.; LOIS, C. Promoción turística y cartografía. La Argentina turística en los mapas de la Secretaría de Turismo de la Nación (19962004). Investigaciones Geográficas, Cidade do Mexico, n. 62, 2007. p. 138-154.

ALONSO MONASTÉRIO, P. Análisis de la eficiencia comunicativa y las funciones interpretativas de los mapas turísticos para la visita de espacios con patrimonio. Tesis (Doctorado) - Departamento de Ingeniería Cartográfica, Geodesia y Fotogrametría. Universitat Politècnica de València, Valéncia, 2013.

BARREIRO, J. B; GONZÁLEZ, R. C. L. Particularidades y estado actual de la cartografía turística oficial en Galicia. Cuadernos de Turismo, Múrcia, n. 26, 2010. p. 25-46.

BERTIN, J. Semiologie Graphique: les diagrammes, les réseaux, les cartes. ParisLa Haye: Mouton/Gauthier-Villars, 1967. 431 p.

CLARKE, L. M. An experimental investigation of the communicative efficiency of point symbols on tourist maps. The Cartographic Journal, London: The British Cartographic Society, v. 26, 1989. p. 105-110.

DOMÍNGUEZ MÚJICA, J. D. La cartografía en la promoción turística de Canarias (1880-1970). Boletín de la AGE, Madrid, v. 44, 2007. p. 279-300.

FORREST, D. On the design of point symbols for tourist maps: enclosed or not enclosed is not the question! The Cartographic Journal, London: The British Cartographic Society, v. 35, 1998. p. 79-81.

FORREST, D.; CASTNER, H. W. The design and perception of point symbols for tourist map. The Cartographic Journal, London: The British Cartographic Society, v. 22, n. 1, 1985. p. 11-29. 
GERBER, R., BURDEN, P.; STANTON, G. Development of public information symbols for tourism and recreational mapping. The Cartographic Journal, London: The British Cartographic Society, v. 27, n. 2, 1990. p. 92-103.

GODINHO, R. G.; OLIVEIRA, I. J. Análise e avaliação da distribuição geográfica da infraestrutura turística no sítio histórico de Pirenópolis (GO): subsídios ao planejamento turístico. Boletim Goiano de Geografia, Goiânia, v. 30, n. 1, 2010. p. 107-122.

INE - Instituto Nacional de Estadística, 2014.España en cifras 2014. Disponível em: <http://www.ine.es/prodyser/espa_cifras/2014/files/assets/basic-html/ page51.html>.Acesso em: 15 maio 2015.

KOKKONEN, P.; PELTONEN, A. Mapping lakelands: challenges of map design for tourism. In: International Cartographic Conference, 19., Abstracts...Ottawa, 1999.

MARTINELLI, M. Curso de cartografia temática. São Paulo: Contexto, 1991.

MENEZES, P. M. L. de; FERNANDES, M. do C. Cartografia turística: novos conceitos e antigas concepções ou antigos conceitos e novas concepções. In: Congresso Brasileiro de Cartografia, 21., Anais... Belo Horizonte, 2003.

MORRISON, C.; FORREST, D. A study of point symbol design for computer based large scale tourist mapping. The Cartography Journal, London: The British Cartographic Society, v. 32, 1995. p.126-136.

OLIVEIRA, I. J. A cartografia aplicada ao planejamento do turismo. Boletim Goiano de Geografia, Goiânia, v. 25, n. 1-2, 2005. p. 29-46.

. Cartografia turística para a fruição do patrimônio natural da Chapada dos Veadeiros (GO). Tese (Doutorado em Geografia) - Universidade de São Paulo, São Paulo, 2007.

OLIVEIRA, I. J.; ROMÃO, P. A. Linguagem dos mapas: utilizando a cartografia para comunicar. Goiânia: Ed. UFG, 2013.

OSTROWSKI, J.; OSTROWSKI, W. Cartographic conception of tourist map softowns. International Yearbook of Cartography, 1975. p.123-132.

PEARCE, D. G. Geografia do turismo: fluxos e regiões no mercado de viagens. São Paulo: Aleph (Série Turismo), 2003. 388 p.

RIBERA, D. I. B. Cartografia per al turisme. Segon Congrés Català de Geografia. 29-31 maio, 2008.

TABOADA-DE-ZÚÑIGA, P. Una aproximación al turismo idiomático en España. El caso particular de las ciudades históricas. Nuevas perspectivas del turismo para la próxima década. III Jornadas de Investigación en Turismo / coord. por José Luis Jiménez Caballero, Pilar de Fuentes Ruiz, 2010, ISBN 978-84-693-27111, 2012. p. 757-782.

TABOADA-DE-ZÚÑIGA, P. El turismo idiomático en Santiago de Compostela. Tese (Doutorado) - Universidade de Santiago de Compostela, Santiago de Compostela, 2014. 
TUJAKA, D. Uso de cartografía para mejorar la imagen proyectada del destino turístico en el entorno Web. XII Coloquio de Geografía del Turismo, Ocio y Recreación: Espacios y destinos turísticos en tiempos de globalización y crisis (AGE), Universidad Carlos III (Madrid), 2011.

Ivanilton José de Oliveira - Possui graduação em Administração de Empresas pela Faculdade Anhanguera de Ciências Humanas. Licenciatura e Bacharelado em Geografia pela Universidade Federal de Goiás. Mestrado e Doutorado em Geografia pela Universidade de São Paulo. Possui Pós-Doutorado pela Universidad de Santiago de Compostela - Campus Santiago. Atualmente é professor adjunto da Universidade Federal de Goiás.

Pilar Taboada-de-Zuñiga Romero - Licenciada en Filoloxía Románica pela University of Southern California, Diplomada en Empresas e Actividades Turísticas pela Escola Oficial de Madrid, e Máster Oficial Interuniversitario em Dirección e Planificación de Turismo da Universidade de Santiago de Compostela. Doutora en Dirección e Planificación turística pela Universidade de Santiago de Compostela. Atualmente trabalha no Centro de Estudos e Investigacións Turísticas como Investigadora, realizando trabalhos relacionados à docência e pesquisa e tanto a nível local quanto internacional.

Recebido para publicação em 2 junho de 2015 Aceito para publicação em 18 julho de 2015 